\title{
Bio-assay evidence of abnormal secretin-like and gastrin-like activity in tumour and blood in cases of 'choleraic diarrhoea'
}

\author{
I. G. M. CLEATOR, CHRISTINE G. THOMSON, W. SIRCUS ${ }^{1}$, AND \\ MIRANDA COOMBES \\ From the Gastro-Intestinal Unit, and the Teaching and Research Centre, Western General \\ Hospital, Edinburgh
}

SUMMARY Methods for bio-assay of secretin-like humoral agents in both cat and dog are described. Bio-assay of tumour extracts and of plasma from patients with the pancreatic choleraic syndrome are described. The first patient was found to have choleretic and secretinlike activity in an extract of her pancreatic islet cell tumour and gastrin-like activity in her plasma. The second patient was found to have both secretin and gastrin-like activity in her plasma, as well as choleretic activity.

It is concluded that at least part of the profuse, watery electrolyte diarrhoea of the 'pancreatic cholera' syndrome associated with peptide-secreting adenoma of the pancreas is likely to be a reflection of the excessive production of secretin, as well as of gastrin, and possibly also of a choleretic agent.

The variety of clinical presentations associated with hyperplasia or tumour of the islet cells of the pancreas and with secretion of peptides has been referred to (Sircus, Brunt, Walker, Small, Falconer, and Thomson, 1970) and reviewed in detail (Sircus, 1969). It has recently been suggested (Zollinger, Tompkins, Amerson, Endahl, Kraft, and Moore, 1968) that 'pancreatic cholera' may be caused by a secretin-like hormone elaborated by an islet cell tumour. The purpose of this paper is to present the results, including bioassay of plasma and of tumour extracts, of studies on two patients with choleraic diarrhoea, together with an examination of the influence of tumour extracts upon water and ion transport across the canine intestinal mucosa.

\section{Methods}

EXPERIMENTAL TECHNIQUE

Cat bio-assay

A cat, $2.5 \mathrm{~kg} / \mathrm{bw}$, was anaesthetized using ethyl${ }^{2}$ Member of the external scientific staff, Medical Research Council. chloride and ether for induction followed by $200 \mathrm{mg}$ intravenous chloralose. No further anaesthetic was required throughout the procedure. A cuffed tracheotomy tube was inserted to prevent aspiration of secretions. The main pancreatic duct was cannulated with a polythene cannula, $0.63 \mathrm{~mm}$ in diameter, which was ligated in position. The common bile duct was separately cannulated using a $1.02 \mathrm{~mm}$ diameter polythene cannula, and both cannulae were brought out through stab wounds to establish dependent drainage. A cannula in the external jugular allowed a constant infusion of saline at the rate of $0.076 \mathrm{ml} / \mathrm{min}$ using a Harvard continuous delivery pump. The cat's temperature was kept constant at $38^{\circ} \mathrm{C}$.

The output from both cannulae was collected continuously into graduated tubes which were changed every 15 minutes. After an hour of basal collections, the intravenous injections were made at intervals of 30 to 60 minutes using as a guide to procedure the volumes of secretions recovered. These injections were an extract of a neuroblastoma, an extract from the adenoma removed from the first case of choleraic diarrhoea (E.S.), plasma from a subject with suspected lymphoma of the small intestine but with a normal pancreas, 
and plasma from the second case of choleraic diarrhoea (A.G.). After the completion of these observations, secretin (Boots) was added to the saline and infused at the rate of $9 \cdot 1 \mathrm{units} / \mathrm{kg} / \mathrm{bw} /$ 60 minutes. When the volume output from the pancreas had reached a steady state further intravenous injections were made at intervals of 30 to 60 minutes. These were an extract of the neuroblastoma, an extract of the adenoma from the first case of choleraic diarrhoea (E.S.), plasma from the second case of choleraic diarrhoea (A.G.), plasma obtained from the first case of choleraic diarrhoea subsequent to removal of the adenoma (E.S.), and plasma from the patient with suspected intestinal lymphoma.

\section{Dog bio-assay}

A mongrel dog, $21.5 \mathrm{~kg} / \mathrm{bw}$, was initially anaesthetized with $10.5 \mathrm{ml}$ of nembutal and subsequently with hourly injections of $1-1.5$ millitres. The airway was maintained with a cuffed endotracheal tube.

The operation was a modification of that described by Lin and Alphin (1962) and Zollinger et al (1968). The main pancreatic duct was cannulated extraduodenally with a $1.02 \mathrm{~mm}$ polythene tube, and the common bile duct with a $1.34 \mathrm{~mm}$ polythene tube ligated in position. Two accessory ducts were found and ligated. The cystic duct was ligated to prevent the gallbladder emptying during the course of the experiment, and the pylorus ligated to prevent stimulation of the duodenum by gastric contents. A cannula (1 $\mathrm{cm}$ diameter) was introduced into the fundus of the stomach and this, as the other two, brought out through a stab wound and arranged to drain dependently into a graduated tube. A constant infusion of saline at the rate of $0.076 \mathrm{ml} / \mathrm{min}$ was begun using the right femoral vein.

The output of the three cannulae was collected continuously, the tubes being changed at 15minute intervals, and after two hours of basal collections a single injection was made of an extract from the pancreatic adenoma of the first case (E.S.). One and three quarter hours later, secretin was added to the saline and infused at the rate of 1.7 units $/ \mathrm{kg} / \mathrm{bw} / 60$ minutes. A steady output of pancreatic secretion was established and the effect observed of, first, an intravenous injection of an extract from the tumour of the first case (E.S.) and, subsequently, of plasma from the second case (A.G.).

\section{Rat bio-assays}

Plasma from lithium-heparinized blood was obtained from the first case (E.S.) before, during, and after the removal of the tumour. Multiple assays using a technique described elsewhere (Thomson, Cleator, and Sircus, 1970) were subsequently carried out. withdrawn into lithium-heparin tubes. After centrifuging at $5^{\circ} \mathrm{C}$ the resulting plasma was stored at $-20^{\circ} \mathrm{C}$, and just prior to assay, thawed at not greater than $30^{\circ} \mathrm{C}$ and recentrifuged at $5^{\circ} \mathrm{C}$ to remove fibrin. The resulting plasma was then assayed with no further manipulation.

After excision the tumour had been rapidly placed in a plastic bag and then dropped into a solid $\mathrm{CO}_{2}$ alcohol bath. This allowed rapid freezing of the tissue which was thereafter stored at $-20^{\circ} \mathrm{C}$ until required. The method used for tumour extraction was essentially that described by Zollinger et al (1968).

Frozen tumour tissue $(3.4 \mathrm{~g})$ from patient E.S. was homogenized in increasing volumes of $0.1 \mathrm{M} \mathrm{HCl}$ until a final volume of $57 \mathrm{ml}$ was achieved. The homogenizer vessel was chilled in ice water during this procedure. After filtration with suction on glass paper (Whatman GF/A), the filtrate was brought to $30 \% \mathrm{NaCl}$ concentration by the slow addition, with stirring, of solid $\mathrm{NaCl}$. A precipitate gradually formed and after standing at $4^{\circ} \mathrm{C}$ for 20 minutes was centrifuged, to yield a light brown precipitate, the filtrate being clear. After decanting the filtrate, the precipitate was stirred and then shaken with $6.0 \mathrm{ml}$ ice-cold acetone in a stoppered tube. The acetone powder, which was pale cream in colour, was dried under suction and washed on the filter with more acetone until completely dry. The final material $(0.97 \mathrm{~g})$ was then stored at $-20^{\circ} \mathrm{C}$ in a desiccator until required for assay. Similar powders were prepared from other portions of the same tumour and also from the neuroblastoma control.

Just before assay, a $5 \%$ aqueous suspension was prepared and filtered after shaking. Appropriate volumes (see Figs 1, 2,3) were then injected.

Tumour tissue was also extracted to test for gastrin-like activity using a modification of the procedure of Gregory and Tracy (1964) known to yield active extracts from normal human antrum.

\section{COLLECTION OF SAMPLES}

In both experiments the tubes in which the juice from the cannulae was collected were capped with a thin rubber diaphragm and partially immersed in iced water to minimize the loss of bicarbonate. Every 15 minutes the collecting tubes were changed and the volume was made up to a manageable volume with distilled water. Each sample was then immediately drawn into glass syringes which were sealed temporarily, maintained at $0^{\circ} \mathrm{C}$, and then stored at $-20^{\circ} \mathrm{C}$.

EFFECT ON WATER AND ION TRANSPORT These studies were done in the Department of Surgery of the University of Cardiff. Several extracts of the tumour of the first case were prepared using different methods and injected intra- 
venously into dogs equipped with Thiry-Vella intestinal loops.

\section{Results}

\section{CAT BIO-ASSAY}

The effect on basal secretion

No biliary secretion was observed throughout the whole experiment, nor did any change appear in the pancreatic flow after injection of the extract of a neuroblastoma, nor after either plasma. Within two minutes, however, of the injection of the extract from the tumour of subject E.S., pancreatic juice dripped from the cannula in the main duct and a total of $0.2 \mathrm{ml}$ was secreted over the next 10 minutes after which secretion ceased. The product of this small but definite response was analysed for bicarbonate, amylase, and protein (Figure 1).

\section{The effect on stimuluted secretin}

The results of the intravenous injections superimposed upon the steady pancreatic flow stimulated by submaximal infusion of secretin as described above proved as follows (Figure 1). The injection of neuroblastoma extract, plasma from the first case of choleraic diarrhoea, and of plasma from the lymphoma control had no effect upon pancreatic flow. The injection of the extract of the tumour from case 1 (E.S.) was followed after a short latent period by a rise in volume which persisted for ten minutes before the output returned to baseline. The injection of plasma from case 2 (A.G.) was followed after a latent interval of two minutes by a rise in volume which did not return to the baseline for 75 minutes. The subsequent chemical analyses of the effluents after these two secretion-provoking injections proved different. The concentrations of both bicarbonate and amylase rose above normal in the response to the tumour extract, suggesting that the active agent, though having secretin-like activity, also contained some other substance which was capable of stimulating the secretion of enzyme. Only a small rise in concentration of bicarbonate accompanied the marked increase in volume after the injection of plasma from the second case but the dramatic fall to undetectable concentrations of amylase and protein is consistent with the effects of secretin (Harper, 1967).

DOG BIO-ASSAY

There was no spontaneous secretion from the dog pancreas, and the injection of tumour extract from E.S. failed to provoke secretion. However, there was a small secretion of bile throughout the course of this part of the experiment and a slight rise in volume occurred after the injection (Figure 2). Gastric secretion was collected in decreasing

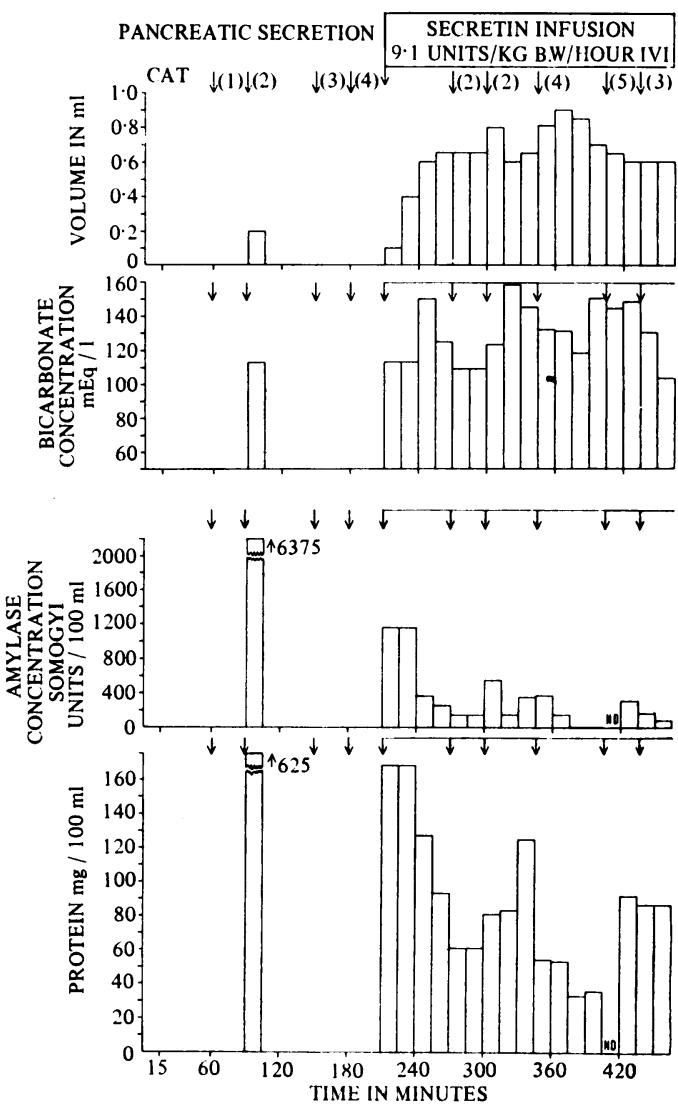

Fig. 1 Composition of pancreatic secretion from the cat preparation. Where test materials were injected intravenously they are indicated: (1) $10 \mathrm{ml}$ neuroblastoma extract, (2) $10 \mathrm{ml}$ extract of adenoma from patient E.S.. (3) $5 \mathrm{ml}$ plasma from 'control' patient, (4) $5 \mathrm{ml}$ plasma from patient A.G., and (5) $5 \mathrm{ml}$ plasma from patient E.S. postoperatively.

quantities for the first two-hour period, and thereafter was zero, or less than $0.2 \mathrm{ml}$ per 15 minutes.

After the intravenous infusion of secretin commenced there was a twofold increase in the output of bile which immediately stabilized. Gastric juice remained absent, or less than $0.5 \mathrm{ml} / 15$ minutes. When the tumour extract of E.S. was injected intravenously, there was a short-lived rise in volume of pancreatic juice without increase in bicarbonate concentration. The change in volume was again limited to a period of 15 minutes and was accompanied by a fall in protein concentration. No effect was observed on the bile or on the gastric secretion (Figure 3).

When plasma from A.G. was injected a rise in volume of pancreatic secretion began within a few minutes and rose progressively to a maximum in the fourth 15-minute period (Figure 3). This was accompanied by a late and slight rise in 
GASTRIC SECRETION DOG

$\downarrow$ (1)
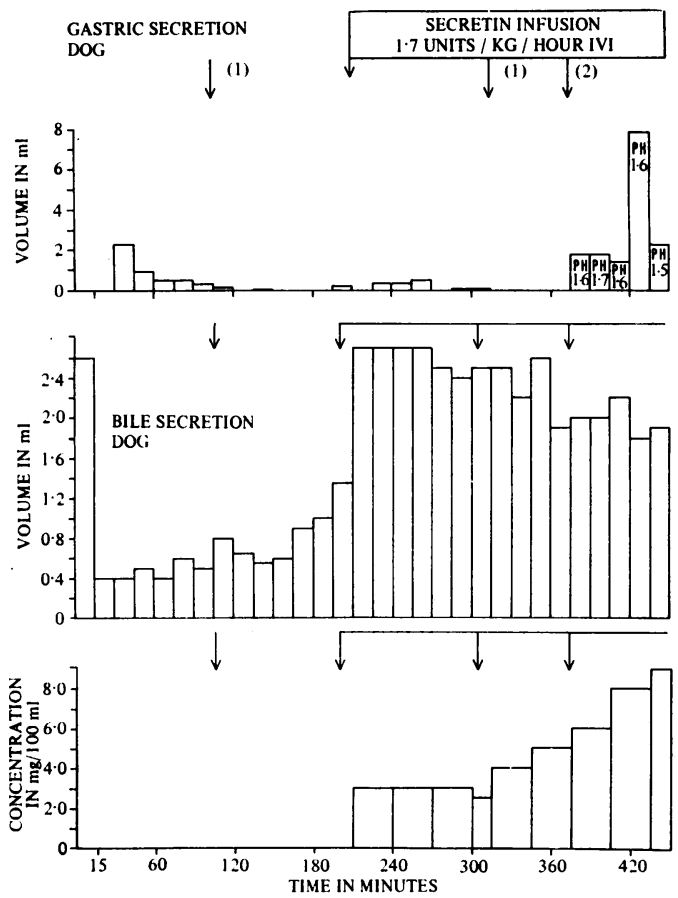

Fig. 2 Biliary and gastric secretion from the dog preparation. Where test materials were injected intravenously they are indicated in Figures 2 and 3. (1) $10 \mathrm{ml}$ extract of adenoma from patient E.S., (2) $5 \mathrm{ml}$ plasma from patient A.G.
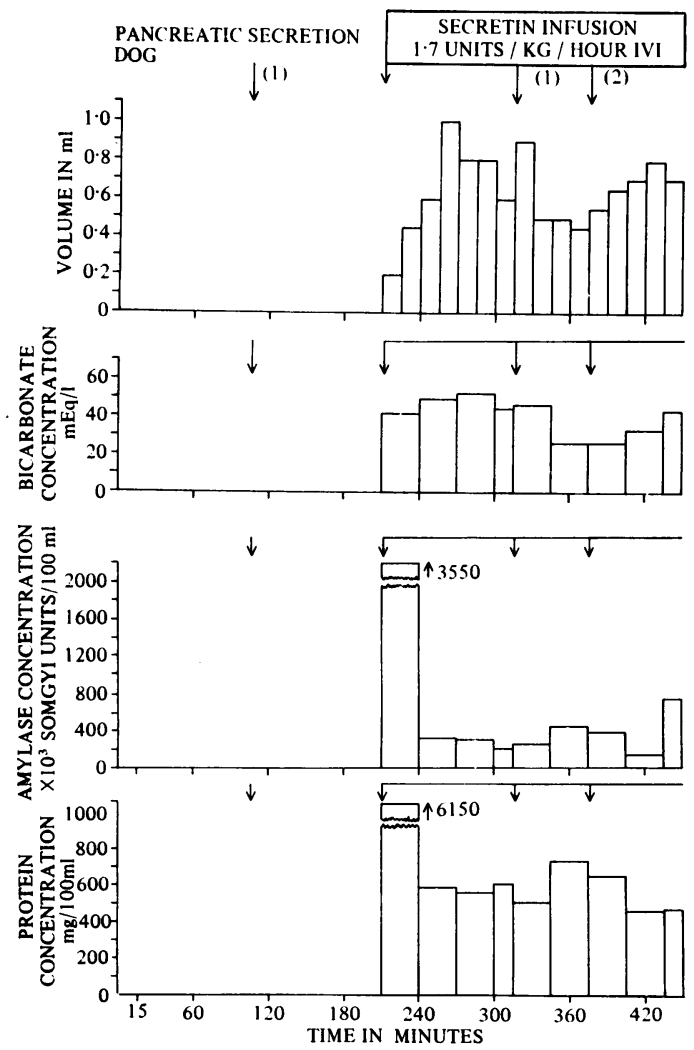

Fig. 3 Composition of pancreatic secretion from the dog preparation. bicarbonate concentration and by a clear fall in protein concentration. Bile secretion was unaffected (Fig. 2), and the volume of gastric secretion rose within a few minutes from zero to $3.7 \mathrm{ml}$ in the first 15 minutes and reached a maximum of $8 \mathrm{ml}$ in the fourth 15 -minute collection period (Figure 2).

During the priming infusion of secretin in the dog, the injection both of the extract of the tumour of E.S. and the plasma of A.G. was followed by an increased concentration of bilirubin without any change in the volume of secreted bile (Figure 2). Zollinger et al (1968) reported a rise in bile flow following injection of extracts of liver metastases into an anaesthetized dog but provided no data.

Permucosal ion and water transport in the dog The intravenous injection of none of the different extracts of the tumour from E.S. had any effect upon the observed transport of water, sodium, chloride, or potassium through the mucosa of Thiry-Vella intestinal loops in perfusion experiments.

\section{RAT BIO-ASSAYS}

Plasma removed from patient E.S. before and during operation did not give clear-cut assay results but a sample taken 15 days after the removal of the tumour gave unequivocal evidence of gastrin-like activity. A further sample 15 days later was negative. Subsequent serial assays have continued to be negative. The plasma used in the dog and cat bio-assays had previously been shown to have no detectable gastrin-like activity in rat bio-assays. Plasma from A.G. on several occasions did not show gastrin-like activity in rat bio-assays. Tumour from E.S. extracted for gastrin activity did not produce acid secretion in a sensitive anaesthetized rat preparation.

\section{Discussion}

Secretin injected into the cat or dog produces an increase in the volume of pancreatic secretion and in the concentration of bicarbonate. Simultaneously there is a fall in the concentrations of protein, amylase, and chloride (Harper, 1967). These criteria are conventionally adopted in deciding if plasma or tissue extract has secretinlike activity. Zollinger et al (1968) found extracts of liver metastases from a pancreatic tumour injected into anaesthetized dogs caused a significant increase in the volume of pancreatic juice, an increase in the bicarbonate concentration, but a fall in protein concentration. The effects of pancreozymin, glucagon, gastrin, 'pentagastrin', histamine, serotonin, prostaglandins, and synthetic secretin were examined by these workers and only the natural and synthetic secretin gave a similar response to that produced by the tumour extracts. 
Extracts of tumour from our first case of choleraic diarrhoea (E.S.) caused a secretion of juice from the otherwise unstimulated pancreas in the cat but not in the dog. This could mean that the cat is more sensitive to the secretin-like hormone than the dog, or alternatively, that the response was influenced by the function of dose/ $\mathrm{kg}$ body weight, the cat being a sixth of the weight of the dog. The volume of juice provoked from the unstimulated pancreas of both animals by the tumour extract was very small, and therefore we decided to 'prime' the pancreas of both with an infusion of secretin. The dose of secretin in each infusion was that which, by prior experimentation, we found would give a low but steady output of pancreatic secretion. In the case of the cat this was 9.1 units Boots secretin $/ \mathrm{kg}$ body weight/hour and in the case of the dog 1.7 units/ $\mathrm{kg}$ body weight/hour. When this was done the extract of tumour from the first case caused an augmentation of the pancreatic output with the characteristics of a secretin-like response in both dog and cat. The response to the extract was rapid in onset and short in duration. We did not obtain the order of volume increase found by Zollinger et al (1968). The reason for this may be twofold. First, the known variability of potency in different tumours, and second, an unknown and variable loss of activity which may occur when tissue is stored at $-20^{\circ} \mathrm{C}$ prior to preparation of an extract.

The implication of the rat bio-assay results has been considered in the companion paper (Sircus et al, 1970). The finding of gastrin-like activity in the plasma of A.G. when given to the dog, although previously no gastrin-like activity had been detected by rat bio-assay, is difficult to explain. However, the dog is known to be considerably more sensitive to gastrin than is the rat (Kahlson, Rosengren, Svahn, and Thunberg, 1964) and the difference in response to the serum between the two animals may be a reflection of this difference in sensitivity.

Assay of plasma from patients with 'pancreatic cholera' for secretin-like activity has not, to our knowledge, previously been carried out. Plasma from the second case of choleraic diarrhoea had no effect on secretion of the pancreas of the cat until after priming with an infusion of secretin. Priming with secretin therefore seems to increase the sensitivity of the bio-assay sufficiently to detect smaller concentrations of circulating pancreatic secretagogue activity, as evidenced by an increase in volume and fall in protein and amylase concentration. However, we did not detect a significant rise in bicarbonate concentration.

The addition of a gastric cannula to the bioassay preparation of the dog (Lin and Alphin, 1962) provided additional information on the plasma of the second patient. The sudden pouring out of a large quantity of gastric juice of low $p \mathrm{H}$, immediately after the injection of the plasma sample and lasting for one hour, indicates that the plasma contained, in addition to its secretinlike activity, a gastric secretagogue. It is extremely unlikely that this outpouring of acid in the dog in response to an injection of only $5 \mathrm{ml}$ plasma could be produced by anything other than a gastrinlike substance. Law and his colleagues (Law, Liddle, Scott, and Tauber, 1965) have studied a patient who appeared to have 'pancreatic cholera' and developed hypocalcaemia, hypokalaemia, and extreme hyperchlorhydria. Bioassay of an extract of pancreatic tumour found at laparotomy showed gastrin-like activity, as well as ACTH and MSH activity. The clinical history suggests that the tumour produced a secretinlike hormone in addition. In our patients we postulate that neither gastrin nor secretin was present at the same time or that a single peptide substance had the capacity for exhibiting secretinlike and gastrin-like activity. Neither of our patients gave reason to suspect tumour secretion of ACTH or MSH activity.

Plasma taken from the first patient (E.S.) subsequent to removal of the tumour, which was negative for gastrin activity in the rat bio-assay, had no effect on volume, bicarbonate concentration and chloride concentration in a bio-assay on the cat primed with secretin.

No diarrhoea occurred in any of the anaesthetized animals during the assays. Zollinger et al (1968) reported that intravenous administration of tumour extract from their patient provoked explosive diarrhoea and retching in a conscious dog, but not when the extract was given to anaesthetized animals. It is of interest to note that Wormsley (1968) observed explosive, painless diarrhoea in two human subjects after intravenous infusion of 10 or 25 units secretin $/ \mathrm{kg} /$ hour; he did not carry out any studies on anaesthetized subjects.

We have demonstrated the presence in the tumour of the first case of a pancreatic secretagogue with secretin-like characteristics, and with choleretic activity in terms of increased concentration of bilirubin in the bile. This choleretic character raises the possibility that the tumour elaborated small quantities of glucagon but we had insufficient remaining tissue to allow us to examine this. That this patient also was episodically elaborating gastrin in excess is suggested by the clinical observations on her gastric secretion (Sircus et al, 1970) and by the plasma bio-assays on the rat. The variability of biochemical activity reflected in the variation of clinical features has already been stressed, and until this phenomenon has been elucidated, one cannot meaningfully discuss the significance of the failure to extract gastrin from the tumour, although an excess was clearly present on occasions in her circulation.

The second subject again serves to emphasize the multiplicity of agents, or possibly the secretagogue multipotentiality of a single agent, elaborated in these disorders. It seems probable 
that multiple factors are responsible for the profuse watery electrolyte-losing diarrhoea, one of which may be an excessive production of secretin.

In respect both of the clinical and experimental studies we wish to accord our gratitude to Mr R. Shields, Reader in Surgery of the United Cardiff Hospitals, and his technical assistant, Mr Calvin Ryan, for the studies they made on the effect of the tumour extract on water and ion transport. We are indebted to Dr D. Horn, Director of the Department of Clinical Chemistry at the Western General Hospital, for the estimations of electrolytes and enzymes on the pancreatic secretions, and to our alimentary function technical staff nurses, Mrs A. Davies and Mrs S. Sandison, for their work.

We received every facility to allow us to carry out the dog and cat studies through the courtesy of $\mathrm{Mr}$ I. B. Macleod, Director of Research, and $\mathrm{Mr} \mathrm{N}$. Samuel, chief technician, of the Department of Clinical Surgery, University of Edinburgh, whom we would wish to thank.

We are grateful for the detailed help and criticism in the preparation of the paper which we received from our colleagues Dr P. W. Brunt and Dr R. J. Walker.

\section{References}

Gregory, R. A., and Tracy, H. J. (1964). The constitution and properties of two gastrins extracted from hog antral mucosa. Gut, 5, 103-114.

Harper, A. A. (1967). Hormonal control of pancreatic secretion. In Handbook of Physiology Sect. 6, Alimentary Canal, edited by C. F. Code, Vol. 2, Secretion, pp. 969-995. American Physiological Society, Washington, DC.

Kahlson, G., Rosengren, E., Svahn, D., and Thunberg, R. (1964). Mobilisation and formulation of histamine in the gastric mucosa as related to acid secretion. J. Physiol. (Lond.), 174, 400-416.

Law, D. H., Liddle, G. W., Scott, H. W., Jr., and Tauber, S. D. (1965). Ectopic production of multiple hormones (ACTH, MSH and gastrin) by a single malignant tumor. New Engl. J. Med., 273, 292-296.

Lin, T. M., and Alphin, R. S. (1962). Comparative bio-assay of secretin and pancreozymin in rats and dogs. Amer. $J$. Physiol., 203, 926-928.

Sircus, W. (1969). Peptide-secreting tumours with special reference to the pancreas. Gut, 10, 506-515.

Sircus, W., Brunt, P. W., Walker, R. J., Small, W. P., Falconer, C. W. A., and Thomson, C. G. (1970). Two cases of 'pancreatic cholera' with features of peptide-secreting adenomatosis of the pancreas. (Submitted with this paper.)

Thomson, C. G., Cleator, I. G. M., and Sircus, W. (1970). Experiences with a rat bio-assay in the dagnosis of the Zollinger-Ellison syndrome. Gut (In press).

Wormsley, K. G. (1968). Response to secretin in man. Gastroenterology, 54, 197-209.

Zollinger, R. M., Tompkins, R. K., Amerson, J. R., Endahl, G. L., Kraft, A. R., and Moore, F. T. (1968). Identification of the diarrheogenic hormone associated with non-beta islet-cell tumors of the pancreas. Ann. Surg., 168, 502-521. 